\title{
EVOLUCIÓN DEL DERECHO SOCIETARIO Y CONCURSAL EN COLOMBIA
}

\author{
Wilson Iván Morgestein Sánchez ${ }^{2}$
}

En primer lugar, quiero agradecer la invitación que me hizo la Institución Universitaria Politécnico Grancolombiano para participar en este evento académico. De manera especial a la doctora Mónica Fernández, y a colegas y amigos como la doctora Lina Ortegón y el doctor Joaquín Acosta. También a todos aquellos que fueron mis compañeros de esta casa de estudios por algo más de 2 años, durante los cuales presté mis servicios como profesor.

Quiero compartir, a través de esta charla, algunas reflexiones en torno a dos áreas del Derecho Privado, que son de vital importancia para el desarrollo de la empresa: el Derecho de Sociedades y el Derecho Concursal.

Lo primero que quiero precisar es la diferencia conceptual entre las nociones de "empresa" y "sociedad". Es un tema propio de la teoría general del Derecho Comercial, pero también es cierto que en las ciencias económicas estos dos conceptos llegan a confundirse. Incluso en el lenguaje común la gente dice: "Yo trabajo en la empresa", "yo voy a constituir una empresa", "mi papá tiene una empresa", "con unos amigos vamos a montar una empresa", etc. Pero en el mundo del Derecho Continental europeo la empresa es una actividad. Así la define el artículo 25 del Código de Comercio y el inciso segundo del artículo 11 de la ley 510 de 1999: "Se entenderá por empresa toda actividad económica organizada para la producción, transformación, circulación, administración o custodia de bienes o para la prestación de servicios". Ahora bien, la sociedad, es el titular de la empresa, pero adviertan ustedes que según la disposición contenida en ese inciso segundo artículo 11 de la ley 510 de 1999, no siempre para desarrollar empresa es necesario constituir una compañía

\footnotetext{
2 Abogado de la Universidad Santo Tomás de Bogotá, especialista en derecho privado y económico de la Universidad Nacional de Colombia. Magíster en derecho comercial de la Universidad Externado. Profesor de Derecho Privado de las universidades la Gran Colombia y Libre de Colombia en pregrado, especialización y maestría. Autor de más de 20 trabajos académicos incluidos artículos en la base Scopus y el libro derecho de sociedades. Ejerce como abogado litigante y consultor empresarial.
} 
mercantil. He aquí otro error en el que incurren algunos operadores de la actividad empresarial: "Si se quiere hacer empresa se hace necesario constituir una sociedad comercial". Eso no es así, la misma disposición legal dice que hay muchas formas de hacer empresa: las sociedades comerciales, consorcios, joint ventures, uniones temporales, fiducias, contratos de cuentas de participación, etc.

Pues bien, ¿cuál es la relación que existe entre la empresa y el Derecho de Sociedades y el Derecho Concursal? Ya hemos dado un primer elemento, a través de las sociedades comerciales, de las compañías mercantiles se puede hacer empresa; y el Derecho de Sociedades, tal y como lo define el Profesor Pablo Andrés Córdoba, es aquella rama del Derecho que regula la organización y el funcionamiento de las sociedades mercantiles.

Por otra parte, surge aquí otro interrogante: ¿cuál es la noción y la función del Derecho Concursal? En primer lugar, se hace necesario advertir que ya en muchos países no se habla de ley de quiebras sino de regímenes de insolvencia. Lo primero que quiere el legislador es salvar la empresa. Recuerden que la Carta política del 91 erige a la empresa como base del desarrollo económico, como fuente generadora de empleo Ello de manera que la primera finalidad de una ley de insolvencia es la de salvar la empresa, porque en la empresa confluyen y se encuentran inmersos distintos grupos de interés. En un régimen de quiebras, como el que existió en Colombia hasta el año 95, lo que se pretendía era, entre otras cosas, proteger al comerciante; porque el único sujeto que podía acudir a un trámite concursal era el comerciante, a punto tal que si el comerciante incurría en una situación de quiebra era como si cometiera un delito. Entonces, lo que pretende el Derecho Concursal es, como lo sostiene el Máximo Órgano de la Jurisdicción Constitucional: "(...) Conciliar los intereses de los deudores, los acreedores y la sociedad en su conjunto, en el evento de la insolvencia del deudor, con la finalidad de proteger el crédito, bien mediante fórmulas de recuperación del deudor, que le permita pagar ordenadamente, o a través de la liquidación de su patrimonio".

Así las cosas, lo apasionante del Derecho Comercial, de nuestra profesión, de nuestro oficio de abogados, es que el Derecho vive evolucionando a medida que van evolucionando las circunstancias que rodean la vida de los destinatarios de sus normas. El Derecho debe evolucionar al mismo paso que evolucionan las circunstancias que de orden filosófico, político, social, cultural, tecnológico y (sobre todo) económico rodean su construcción, interpretación y aplicación. Esto de manera que uno nunca puede llegar a decir que el Derecho 
llegó a su punto máximo de evolución, como pretenden algunos operadores jurídicos.

Ahora bien, nuestro código de comercio, no expedido a través de una ley sino de un decreto ley del año 71, no ha permanecido incólume en estos 48 años. Ha venido evolucionando, ha venido cambiando, ha intentado marchar al mismo compás que las necesidades del empresario colombiano.

En el año 91, se expidió una nueva Constitución nacional, y muchas de las reformas que se han pretendido introducir y que se han introducido al régimen comercial colombiano tienen como finalidad la de armonizar el código de comercio con los principios y valores consagrados en la Carta política de 1991.

Pero también se hace necesario determinar cuáles han sido las ideas que han inspirado esas diversas reformas al régimen societario y concursal; y si de verdad ellas han contemplado y atendido, de manera efectiva, las necesidades del empresariado colombiano.

Una reforma muy importante fue la introducida por la ley 222 de 1995 (que obedeció a la necesidad de flexibilizar y modernizar el código de comercio de 1971, y de incorporar en él los más significativos avances doctrinarios y jurisprudenciales en materia mercantil). Fue el primer paso hacia la modernización del Sistema Societario y Concursal colombiano, y que impactó profunda y positivamente la forma de hacer empresa en nuestro país. En ella se incorporaron y actualizaron instituciones relevantes para el funcionamiento de las compañías de Derecho Privado tales como la unificación de la normatividad aplicable a las sociedades civiles y comerciales, la escisión, el derecho de retiro, los grupos empresariales, los acuerdos de sindicación de acciones, la forma de convocar el máximo órgano social y de deliberar y votar en asamblea de accionistas o junta de socios, la responsabilidad de los administradores societarios, la constitución de la sociedad anónima por suscripción sucesiva, la fiscalización gubernamental sobre las sociedades comerciales y el régimen de procesos concursales tanto preventivos como liquidatorios. Asimismo, se incorporó a nuestro Derecho de Sociedades la figura de la empresa unipersonal de responsabilidad limitada. Esta figura permitió la introducción al régimen societario patrio de conceptos tales como la "unipersonalidad", el objeto indeterminado, la duración indefinida y la desestimación de la personalidad jurídica societaria. 
Otra reforma importantísima a nuestro Derecho Concursal fue la introducida por la ley 550 de 1999: "Por la cual se establece un régimen que promueva y facilite la reactivación empresarial y la reestructuración de los entes territoriales para asegurar la función social de las empresas y lograr el desarrollo armónico de las regiones y se dictan disposiciones para armonizar el régimen legal vigente con las normas de esta ley". Tal y como lo ha dicho la Corte Constitucional, el propósito perseguido por el Congreso mediante la adopción de esta ley fue el de establecer un marco legal adecuado para que (sin sujeción al trámite concursal vigente en materia de contratos) se pueda convenir la reestructuración de empresas pertenecientes a los sectores productivos de la economía, con agilidad, equidad y seguridad jurídica; especialmente con el fin de promover la reactivación económica y el empleo, hacer más eficiente el uso de todos los recursos vinculados a la actividad empresarial, mejorar la competitividad y promover la función social de los sectores y empresas reestructuradas, restablecer la capacidad de pago de las empresas, facilitar el acceso al crédito, fortalecer la dirección y los sistemas de control interno de las empresas, propender porque las empresas y sus trabajadores acuerden condiciones especiales y temporales en materia laboral que faciliten su reactivación y viabilidad, así como facilitar la garantía y el pago de los pasivos pensionales. Es decir, los objetivos de la ley se orientan hacia la recuperación de las empresas y no de los empresarios, a fin de lograr también la reactivación económica del país.

Ahora quiero referirme a la ley 116 de 2006 por la cual se establece el Régimen de Insolvencia Empresarial en la República de Colombia y se dictan otras disposiciones. Esta ley, que establece un régimen de insolvencia unificado aplicable a las personas naturales, las personas jurídicas y las sucursales de sociedades extranjeras, incorporó al ordenamiento jurídico colombiano la Ley Modelo sobre Insolvencia Transfronteriza de la CNUDMI (Comisión de las Naciones Unidas para el Derecho Mercantil Internacional). Ahora, tal y como lo enseña el Profesor Juan José Rodríguez, la principal virtud del actual régimen de insolvencia empresarial patrio es la de consagrar un sistema único de naturaleza judicial, tanto para el concurso preventivo (acuerdo de reorganización) como para el concurso liquidatorio (liquidación judicial). Esto le otorga a los acreedores y al deudor confianza en el acuerdo, aparte de generar un ambiente de publicidad y transparencia que facilita su negociación. Por otra parte, y habida cuenta de las realidades económicas de nuestro país, la ley 1116 de 2006 consagra la protección del crédito, de la empresa y del empleo; con lo cual se pretende la salvaguarda de la empresa como base del desarrollo económico y el acceso por parte de los trabajadores a los 
ingresos a los que tienen derecho, para de esta forma equilibrar las posiciones del deudor, los acreedores y el ente económico.

Ahora quiero hablar de la evolución reciente de nuestro Derecho Societario. En primer lugar, quiero referirme a la ley 1014 de 2006, de fomento a la cultura del emprendimiento, especialmente a su artículo 22: "Constitución nuevas empresas. Las nuevas sociedades que se constituyan a partir de la vigencia de esta ley, cualquiera que fuere su especie o tipo, que de conformidad a lo establecido en el artículo $2^{\circ}$ de la Ley 905 de 2004, tengan una planta de personal no superior a diez (10) trabajadores o activos totales por valor inferior a quinientos (500) salarios mínimos mensuales legales vigentes, se constituirán con observancia de las normas propias de la Empresa Unipersonal, de acuerdo con lo establecido en el Capítulo VIII de la Ley 222 de 1995. Las reformas estatutarias que se realicen en estas sociedades se sujetarán a las mismas formalidades previstas en la Ley 222 de 1995 para las empresas unipersonales. Parágrafo. En todo caso, cuando se trate de Sociedades en Comandita se observará e requisito de pluralidad previsto en el artículo 323 del Código de Comercio".

Con esta disposición, inspirada en las ventajas prácticas que representaba para el pequeño empresario la flexibilidad normativa contenida en los artículos 71 y 72 de la ley 222 de 1995, se superó de manera definitiva el requisito de pluralidad para la constitución de compañías de pequeñas dimensiones. La norma en cita fue declarada exequible a través de la sentencia C-392 de 2007, y reglamentada mediante decreto 4463 de ese mismo año; $n$ el cual se superó la discusión doctrinaria que giró en torno a la unipersonalidad societaria, y se dejó claro que sí se podían constituir compañías unipersonales de cualquier especie, con excepción de las sociedades comanditarias. Por lo demás, todavía se pueden constituir sociedades microempresarias de cualquier tipo pero con pluralidad de asociados, con objeto indeterminado, duración indefinida y mediante documento privado inscrito en Cámara de Comercio (excepción hecha de que los constituyentes aporten a la compañía bienes inmuebles, caso en el cual se debe otorgar escritura pública para así dar cumplimiento a las reglas que sobre la materia contiene nuestro Código Civil).

Ahora es momento de hablar de la ley 1258 de 2008, por medio de la cual se crea la sociedad por acciones simplificada. La sociedad por acciones simplificada se erige como una de las más exitosas especies societarias en los últimos años de historia 
legislativa en Latinoamérica, Así lo demuestra el interés que despertó en organismos internacionales como la Organización de Estados Americanos, cuyo Comité Jurídico le recomendó a la Asamblea General de este organismo la adopción de una ley modelo sobre sociedad por acciones simplificadas teniendo como punto de referencia la ley colombiana 1258 de 2008. Por su parte, la Comisión de las Naciones Unidas para el Derecho Mercantil Internacional, por iniciativa de la Delegación colombiana y con el voto unánime de los países miembros de la comisión, constituyó un grupo de trabajo para analizar la constitución simplificada de sociedades.

La SAS es un tipo societario que concilia elementos tanto de las sociedades de personas como de las de capitales, y habida cuenta de la amplia libertad que inspira su constitución y funcionamiento, se presenta como la especie societaria idónea para las compañías de carácter cerrado. Son varias las razones por las cuales la sociedad por acciones simplificadas es el tipo societario más usado por el empresariado colombiano, dentro de ellas podemos mencionar: (i) Se puede crear mediante contrato o acto unilateral que conste en documente privado, físico o electrónico, inscrito en el Registro Mercantil; (ii) Los accionistas solo responderán hasta el monto de sus aportes, incluso por obligaciones laborales o tributarias; (iii) Puede tener objeto indeterminado; (iv) Puede tener duración indefinida; y (v) Su estructura orgánica tan leve que puede operar tan solo con un representante legal.

Por último, quisiera hablar de la ley 1429 de 2010: "Por la cual se expide la Ley de Formalización y Generación de Empleo". A través del capítulo II del Título IV de la ley denominado "Simplificación de Trámites Comerciales", se incorporó un novedoso sistema de liquidación simplificada de compañías y se crearon reglas en materia de reactivación de sociedades y sucursales en estado de liquidación. El capítulo está integrado por veintiún artículos, los cuales introducen modificaciones y novedades al Régimen Societario y Concursal colombiano en los siguientes temas: determinación de la causal de disolución de una sociedad; liquidación privada de una sociedad sin pasivos externos; depósito de acreencias no reclamadas; adjudicación adicional; acciones contra socios y liquidadores en la liquidación voluntaria; reactivación de sociedades y sucursales en liquidación; otros presupuestos de admisión al proceso de reorganización empresarial. Se incluyen disposiciones comunes sobre liquidación privada; intervención de promotor en los procesos de reorganización; objeciones al proyecto de reconocimiento y graduación de créditos y derechos de voto; término para celebrar el acuerdo de reorganización, plazo y confirmación del acuerdo de adjudicación; utilización de medios electrónicos en los procesos de insolvencia; 
publicidad de los contratos de fiducia mercantil con fines de garantía que consten en documento privado; exclusión de la presentación personal de los poderes para adelantar trámites ante la Superintendencia de Industria y Comercio; así como contribuciones para cubrir los gastos de funcionamiento e inversión que requiera la Superintendencia de Sociedades y facultades en su ejercicio de control.

Por último, quiero agradecer a todos ustedes por esta gentil invitación. De verdad me siento muy complacido de haber vuelto en esta jornada, a esta Universidad tan querida, a esta Universidad que está liderando procesos tecnológicos, académicos y administrativos en el ámbito de la educación superior en Colombia. 